\title{
What Should the Optimal Income Tax Rate Be?
}

\author{
Nissim Ben David*, Garyn Tal Sharon \\ Department of Economics and Management, The Max Stern Yezreel Valley College, Yezreel, Israel \\ Email: *nissimb@yvc.ac.il, sharon.tal.garyn@gmail.com
}

How to cite this paper: David, N.B. and Sharon, G.T. (2019) What Should the Optimal Income Tax Rate Be? Modern Economy, 10, 1946-1962. https://doi.org/10.4236/me.2019.108124

Received: July 10, 2019

Accepted: August 25, 2019

Published: August 28, 2019

Copyright $\odot 2019$ by author(s) and Scientific Research Publishing Inc. This work is licensed under the Creative Commons Attribution International License (CC BY 4.0).

http://creativecommons.org/licenses/by/4.0/

Open Access

\begin{abstract}
In this paper, we present a model that enables us to calculate the optimal income tax rate, given a specific utility function from leisure and consumption of private and public goods. The main contribution of our paper is presenting a new approach for determining the optimal tax rate: instead of focusing on the social planner's point of view, we focus on the private agent's point of view. We assume a given labor supply function and calculate the loss of income which equals increased government supply following tax imposition. Taking into consideration the loss of utility following decreased private consumption as well as increased public utility following increased leisure and public consumption, we calculate the income tax rate that would maximize an agent's benefit. We examined our model by gradually changing labor supply elasticity, wage per hour, and the parameter of marginal utility from public consumption. We find that as labor supply elasticity increases, the optimal tax rate should be lower. On the other hand, as wage per hour increases, the optimal tax rate should be higher. Finally, as the parameter increasing utility from public consumption is lower, the optimal tax is lower.
\end{abstract}

\section{Keywords}

Optimal Tax Rate, Public Consumption, Private Consumption, Leisure

\section{Introduction}

Imposing income tax reduces the net wage per-hour by changing the value of leisure and the supply of labor. Consumption of one extra hour of leisure means less one hour of work and vice versa. In standard textbook analysis, the labor supply curve slopes upward and therefore the supply of labor falls when wages are reduced. This schedule is constructed from the labor-leisure choices made by all workforce participants in the community (see, for example, [1] $)^{1}$.

${ }^{1}$ Text book discussion of labor choice includes a discussion of a backwards bending labor supply curve. Numerous factors prevent the majority of workers from ever reaching the point at which income effect dominates the substitution effect leading to a reduction of working hours following wage increase. 
Reduced labor supply means reduced private consumption. However, the collection of increased income tax enables the government to increase the supply of public goods. As is well known, agents will not invest in or buy public goods. Governments enter as the supplier of goods such as security, army, health, education etc., while forcing each agent to finance the supply of these goods (by imposing taxes). Although public goods are needed and essential for agents ${ }^{2}$, the agents will not acquire such goods due to public goods characteristics (if one agent acquires it, then other agents can have the same benefit, a phenomenon known as the free rider problem). Assuming that government, in the long run, preserves a balanced budget, the question we raise here is what should be the optimal tax rate, or alternatively, what level of public expenses would maximize private agent's benefits? This question has been raised by other researchers. [2] and [3] optimized the tax over the population by selecting the tax rate that maximizes the social utility objective function, assuming skill distribution (which determines the income distribution) among the population and assuming utility that is derived from consumption and leisure. In the [2] model, workers are endowed with heterogenous productivities or skills known only to themselves and to their employers, labor supply varies with work effort and the optimal marginal tax rate is determined for any given income or skill. [3] concentrates on a special case where there is no income effect on the labor supply, such that utility is linear in consumption. [4] suggested a model with $\mathrm{n}$ types of jobs, each of which requires given hours of works and yields a given output. The government imposes tax rate $T_{i}$ on each job (according to income $Y_{i}$ ) and workers consume $C_{i}=Y_{i}-T_{i}$ Those who do not work obtain transfer $C_{0}$ from the government. Workers chose to participate in the labor market based on the return from participation $C_{i}-C_{0}$ and given their disutility from work. Assuming there is no income effect in labor supply, the optimal tax structure is characterized. [5] characterized the optimal tax schedule in a model where the only decision made by individuals is regarding their participation decision. He derived the tax system that maximized government revenue as a function of the distribution of productivities and work opportunity cost.

We use a different approach: instead of focusing on a distribution of workers according to skills, we focused on the private agent's point of view. We discuss the optimal income tax rate given the utility function of an individual from private consumption and leisure consumption and given public utility from public good consumption. Defining a target function that adds the aggregated reduction in marginal benefit from private consumption following the tax imposition, while adding to it the aggregated marginal benefits from the supply of new public goods and the aggregate increase in leisure, we could maximize the function subject to income tax and find the optimal tax rate.

${ }^{2} \mathrm{~A}$ common procedure used to estimate the value of a public good is the contingent evaluation method ([20] [21] [22] [23]). When this method is used, a sample of people is interviewed, and asked to estimate how much they would be willing to pay to preserve a public good. 


\section{Methodology}

Our goal in this paper is to determine the optimal income tax rate that should be charged by the government. Given hourly gross wage $W_{0}$ and an income tax rate that equals zero, individuals choose to work $h_{0}$ hours per day and that determines their leisure level $L_{0}$ as $24-h_{0}$. The benefit to the individual from his working hours per day in terms of money when the income tax rate equals zero is $h_{0} * W_{0}$.

Next, assuming that for the given hourly wage $W_{0}$, the government charges an income tax rate that equal $t$, the individual will now choose to work $h_{1}$ hours per day and his leisure level will be $L_{1}=24-h_{1}$. His benefit from his working hours in terms of money is $h_{1} * W_{0} *(1-t)$. We can now calculate the reduction in the benefit of the individual from his working hours per day in terms of money, after taxes have been charged, as: $h_{0} W_{0}-h_{1} W_{0}(1-t)$ and this expression equals the total daily taxes charged by the government plus the loss in the individual's income following the decrease of motivation caused by the imposed income tax.

In order to decide on the optimal income tax rate, first we should take into consideration the reduction in utility following the reduction in private consumption (income).

Assuming a specific structure for the agent's utility from leisure and consumption, the optimal chosen number of leisure hours fulfills the known condition:

$$
\frac{m u(L)}{m u(x)}=\frac{W_{0}}{p} \Rightarrow m u(L)=\frac{W_{0} * m u(x)}{p}
$$

for $m u(L)$-the marginal utility from leisure, $m u(x)$-the marginal utility from consumption of $x$ (goods), $p$-the price of a unit of $X$ and $W_{0}$-the gross wage per hour.

Let us define the loss in terms of utility units following consumption reduction after tax imposed as $B X$. The utility loss $B X$ is:

$$
B X=\int_{h_{0} W_{0}-h_{1} W_{0}(1-t)}^{h_{0} W_{0}} m u(x)
$$

Second, we should take into consideration that after the tax imposition, agents would have increased their amount of chosen leisure, which leads to increased utility from leisure. Specifically, following the income tax, the individual increases the amount of leisure from $L_{0}$ to $L_{1}$. Defining the individuals' Marginal Benefit from Leisure as $M B L=m u(L)$, we get that the total increase in utility from leisure following the imposed income tax is:

$$
B L=\int_{L_{0}}^{L_{1}} M B L
$$

where, $B L$ represents the increased benefit from increasing leisure level from $L_{0}$ 
to $L_{1}$.

Lastly, after the tax imposition, the public benefits from government-increased services ${ }^{3}$. Assuming a specific structure for the public marginal benefit from public goods, $M B G(t)^{4}$ and integrating on $M B G$, we can get $B G$ :

$$
B G(t)=\int M B G
$$

That allows us to calculate the public's benefit from government products caused by the increase of the tax rate from 0 to $t: B G(t)-B G(0)$.

Next, we should take into consideration the increased utility from the increased amount of public goods and the increased amount of leisure minus the reduction in private consumption following the income tax imposition. We should choose a tax rate that would maximize tax benefits minus tax disadvantages:

$$
B G(t)-B G(0)+[B L-B X]
$$

Thus, in order to find the optimal tax rate, we should derivate Equation (5) and equalize it to zero.

\subsection{Labor Supply Function and Reduced Income Following Imposition of Income Tax}

As a first step, we needed to consider the specific structure of the labor supply curve. According to relevant literature, the elasticity of supply is mostly positive. [6] estimated elasticity of labor supply to be about 0.12. [7] accounted for the wage differential between part time and full time work, and applied four different estimation procedures to estimate uncompensated wage elasticities of women's labor supply. They found elasticities that were always positive. [8] provided a review of estimates of labor supply elasticity. They found several examples of negative wage elasticity estimates. [9] reported backward bending labor supply schedule for self-employed sea-scallop fishermen, who could freely adjust their working hours, unlike employees who are often demand constrained. However, [10] reported that many estimates of elasticities might be biased downwards as a result of the failure to take into account discontinuities in the labor supply function, taxes and non-linear budget constraints.

In order to estimate the specific structure of the labor supply curve and the loss of income following the income tax imposition, let us assume that the individual's utility from consumption $X$ and leisure $L$ is ${ }^{5}$ :

$$
U(X, L)=L^{\alpha}+X^{\beta}
$$

where, $X=W_{0}(1-t)(24-L)$, and $\beta$ and $\alpha$ are smaller than 1 .

\footnotetext{
${ }^{3}$ Assuming that tax finance government expenses, as in [3].

${ }^{4}[24]$ measured marginal benefit of a pure public good by the sum of the marginal rate of substitution between the public good and a reference private good. In effect, the amount of reference private good that people would be willing to give up in exchange of public good.

${ }^{5}$ [2] assumed the utility function is $U=\log (x)+\log (L)$. [3] assumed a utility that is linear in con-

sumption and concave in leisure $U=X+v(L)$ where $\mathrm{v}$ is strictly concave. [25] presented optimal tax models with non-separable preferences.
} 
The labor supply function derived from such a utility function is ${ }^{6}$ :

$$
h=m *\left(W_{0}(1-t)\right)^{n}
$$

Notice that changing only the parameter $n$ in Equation (7) changes the elasticity of supply.

The specification in Equation (7) can apply to upward or backward bending labor supply, depending on the parameter $n$, where $n$ represents the elasticity of labor supply.

In general, given gross hourly wage $W_{0}$ and income tax rate $t$, the individual chooses to work $h$ hours and his leisure ( $L$, which is between 0 and 24) is defined via the following equation:

$$
L=f\left(W=W_{0}, t\right)=24-h=24-m *\left(W_{0}(1-t)\right)^{n}=24-m * W_{0}^{n}(1-t)^{n}
$$

Specifically, given gross hourly wage $W_{0}$ and tax rate that equals zero, the individual chooses to work:

$$
h_{0}=f\left(W=W_{0}, t=0\right)=m * W_{0}^{n}
$$

and thus his leisure level $L_{0}$ when the tax rate is zero is:

$$
L_{0}=24-f\left(W=W_{0}, t=0\right)=24-m * W_{0}^{n}
$$

The benefit of the individual from his/her working hours per day in terms of money is:

$$
h_{0} * W_{0}=m * W_{0}^{n} * W_{0}=m * W_{0}^{n+1}
$$

Assuming that the vertical axes represent wage per hour and the horizontal axes represents the number of daily leisure hours, Figure 1 describes the individual's daily money income which equals the rectangle $\mathrm{ABCD}$.

Now we assume that, for the same gross hourly wage of $W_{0}$, the government charges tax rate that equal to $t$. Thus, the actual net hourly wage to the individual is $W_{0}(1-t)$ and the individual will now choose to work $\mathrm{h}_{1}$ hours:

$$
h_{1}=f\left(W=W_{0}, t=t\right)=m * W_{0}^{n} *(1-t)^{n}
$$

His benefit from his working hours in terms of money is:

$$
h_{1} * W_{0} *(1-t)=m * W_{0}^{n} *(1-t)^{n} W_{0} *(1-t)=m * W_{0}^{n+1} *(1-t)^{n+1}
$$

Figure 2 describes the new state of the agent.

The agent loses an income that is equal to areas $\mathrm{H}+\mathrm{I}+\mathrm{TAX}$ since the agent chooses to work now $h_{1}=24-L_{1}$ hours and he earns a net hourly wage $W_{0}(1-t)$ as opposed to $h_{0}=24-L_{0}$ and $W_{0}$, respectively, before the tax was charged. Out of this, the TAX area is collected by the government. We can ${ }^{6}$ Maximizing utility subject to a budget constraint determines working hours as $\frac{h^{1-\beta}}{(24-h)^{1-\alpha}}=\frac{\beta}{\alpha} W_{0}(1-t)^{\beta}$, for h smaller than 24 , we can write it as $h^{\prime}=m W_{0}(1-t)^{n}$, for $h^{\prime}=\frac{h^{1-\beta}}{(24-h)^{1-\alpha}}$. Notice that $\mathrm{n}$ is the elasticity of $h^{\prime}$ relative to $W_{0}$. As elasticity is larger relative to $h^{\prime}$ it would be higher relative to $h$ and vice a versa. 


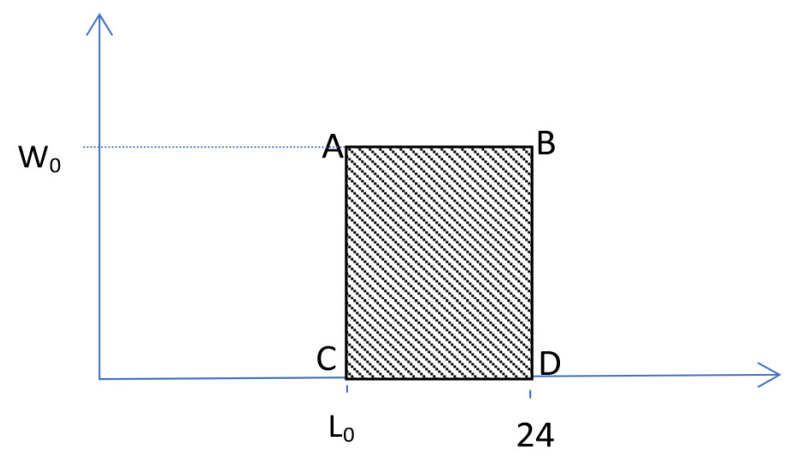

Figure 1. The individual's daily money income.

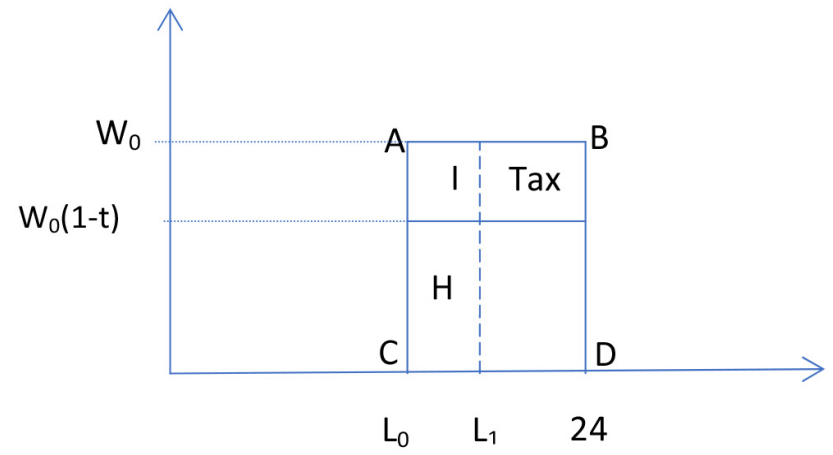

Figure 2. The individual's daily money income following imposition of income tax.

calculate the agent loss areas: the loss in the individual's income following the taxes (or in other words, the reduction in the benefit of the individual from his/her working hours per day in terms of money after taxes have been charged) equals:

$$
h_{0} W_{0}-h_{1} W_{0}(1-t)=m W_{0}^{n+1}-m W_{0}^{n+1}(1-t)^{n+1}=m W_{0}^{n+1}\left(1-(1-t)^{n+1}\right)
$$

Equation (13) equals the total daily taxes charged by the government (the income tax rate $\mathrm{t}$ times the individual's daily gross wage $W_{0} * h_{1}$ (area TAX in Figure 2)), thus:

$$
\mathrm{TAX}=t * W_{0} * m * W_{0}^{n} *(1-t)^{n}=t * m * W_{0}^{n+1} *(1-t)^{n}
$$

plus the loss in the individual's income following the decreased working hours caused by the taxes ${ }^{7}$ (area H+I in Figure 2):

$$
\left(h_{0}-h_{1}\right) W_{0}=\left(m W_{0}^{n}-m W_{0}^{n}(1-t)^{n}\right) W_{0}=m W_{0}^{n+1}\left(1-(1-t)^{n}\right)
$$

$$
\begin{aligned}
& { }^{7} \text { As we can see summing the terms in (14) and (15) we get: } \\
& t * m W_{0}^{n+1}(1-t)^{n}+m W_{0}^{n+1}\left(1-(1-t)^{n}\right) \\
& =m W_{0}^{n+1}\left[t(1-t)^{n}+\left(1-(1-t)^{n}\right)\right] \\
& =m W_{0}^{n+1}(1-t)^{n}[t-1]+m W_{0}^{n+1} \\
& =m W_{0}^{n+1}-m W_{0}^{n+1}(1-t)^{n+1} \\
& =h_{0} W_{0}-h_{1} W_{0}(1-t) \\
& \text { As presented above. }
\end{aligned}
$$




\subsection{Changed Benefits Following Imposition of Income Tax}

\subsubsection{Benefit Loss from Income Reduction}

Following the reduction of working hours from $h_{0}$ to $h_{1}$, income and thus private consumption are reduced. Calculating $B X$-the benefit loss due to consumption reduction assuming the utility function in (6) - we get:

$$
\begin{aligned}
B X & =\int_{h_{0} W_{0}-h_{1} W_{0}(1-t)}^{h_{0} W_{1}} \beta X^{\beta-1} \mathrm{~d} X=\left[X^{\beta}\right]_{h_{0} W_{0}-h_{1} W_{0}(1-t)}^{h_{0} W_{0}} \\
& =\left(h_{0} W_{0}\right)^{\beta}-\left(h_{0} W_{0}-h_{1} W_{0}(1-t)\right)^{\beta}
\end{aligned}
$$

At initial state, if we ignore the government supply of public goods, there is no doubt that from the individual's point of view, the agent suffers from a loss of benefit whenever tax is imposed in term of optimal amount of working hours. Since in initial state (before tax) the agent chose to have $L_{0}$ hours of leisure when s/he had the possibility to have $L_{1}$ hours of leisure, it is certain that from private point of view, or free rider point of view, the individual would prefer that the tax rate be zero. However, when taking into consideration that the government supplies public goods and that the agent benefits from these public goods, we should take this benefit into consideration as well.

\subsubsection{Benefit from Increased Supply of Public Goods}

Public goods give benefits to many agents simultaneously, usually without decreasing the private benefit when more agents use the public good. Let us assume that the agents' marginal benefit from public goods $(M B G)$ is defined as follows:

Given $K(t)$-the marginal money value for the public of each dollar spent by the government ${ }^{8}$, and given $t * W_{0} * h_{1}$ as the amount of public good supplied $^{9}$ in term of dollars, the marginal benefit from government products for every income tax rate $t$ is:

$$
\begin{aligned}
M B G(t) & =K(t) * t * W_{0} *\left(h\left(W_{0}, t\right)\right) \\
& =K(t) * t * W_{0} * m * W_{0}^{n} *(1-t)^{n} \\
& =K(t) * t * m * W_{0}^{n+1} *(1-t)^{n}
\end{aligned}
$$

We assume that:

$$
K(t)=\frac{1}{k * t}
$$

Thus, as $k$ is larger ${ }^{10}$, the importance of the public good for the public is lower; and as $t$ is larger, the amount of supplied public goods is larger and the marginal utility from public good is smaller. Meaning, the importance of the first dollar spent by the government (when $t$ goes to zero) reaches infinity and as the in-

${ }^{8}$ Various factors can affect the benefit from public good, for example, population density positively affects the desirability of public goods.

${ }^{9}$ where $t$ starts at zero and increases gradually.

${ }^{10} \mathrm{k}$ can represent the level of development of the economy. As an economy is more developed and has a better infrastructure of supply of public goods, $k$ is larger and the importance of supplied public goods is smaller. 
come tax rate increases, its importance decreases. Figure 3 presents the connection between tax rate $t$ and $K(t)$.

Substituting (17a) into (17), the marginal utility $M B G$ for various possible levels of tax rate $t$ is:

$$
M B G(t)=\frac{1}{k * t} * t * m * W_{0}^{n+1} *(1-t)^{n}=\frac{1}{k} * m * W_{0}^{n+1} *(1-t)^{n}
$$

Figure 4 presents the connection between the income tax rate $t$ and $M B G$, the marginal benefit from public goods.

Note that $M B G$ s shape depends on $n$.

Note that $M B G=0$ if $t=1$, because there is no point in raising the tax rate above 1 .

Integrating on $M B G$ we get $B G$, the utility from public goods:

$$
\begin{aligned}
B G(t) & =\int M B G=\int\left(\frac{1}{k} * m * W_{0}^{n+1} *(1-t)^{n}\right) \mathrm{d} t \\
& =B-\frac{1}{k(n+1)} * m * W_{0}^{n+1} *(1-t)^{n+1}
\end{aligned}
$$

where, $B$ is a constant.

Since $B G$ is 0 when tax rate is zero, we get:

$$
\begin{aligned}
& B G(t=0)=B-\frac{1}{k(n+1)} * m * W_{0}^{n+1} *(1-0)^{n+1}=B-\frac{1}{k(n+1)} * m * W_{0}^{n+1}=0 \\
& \Rightarrow B=\frac{1}{k(n+1)} * m * W_{0}^{n+1}
\end{aligned}
$$

Thus, $B G$ equals:

$$
B G(t)=\frac{1}{k(n+1)} * m * W_{0}^{n+1}-\frac{1}{k(n+1)} * m * W_{0}^{n+1} *(1-t)^{n+1}
$$

and the benefit from government products caused by the increase of the tax rate from 0 to $t$ is $^{11}$ :

$$
B G(t)-B G(0)=\frac{1}{k(n+1)} * m * W_{0}^{n+1} *\left(1-(1-t)^{n+1}\right)
$$

Figure 5 presents the connection between the income tax rate $t$ and the total benefit that an individual gets from the supply of public goods.

\subsubsection{Benefit from Extra Leisure}

Following the imposition of the income tax rate $t$, the agent gets higher leisure

${ }^{11}$ The benefit from government products caused by the increase of the tax rate from 0 to $t$ is calculated as:

$$
\begin{aligned}
B G(t)-B G(0) & =\frac{1}{k(n+1)} * m * W_{0}^{n+1}-\frac{1}{k(n+1)} * m * W_{0}^{n+1} *(1-t)^{n+1} \\
& -\left(\frac{1}{k(n+1)} * m * W_{0}^{n+1}-\frac{1}{k(n+1)} * m * W_{0}^{n+1} *(1-0)^{n+1}\right) \\
& =-\frac{1}{k(n+1)} * m * W_{0}^{n+1} *(1-t)^{n+1}+\frac{1}{k(n+1)} * m * W_{0}^{n+1} \\
& =\frac{1}{k(n+1)} * m * W_{0}^{n+1} *\left(1-(1-t)^{n+1}\right)
\end{aligned}
$$




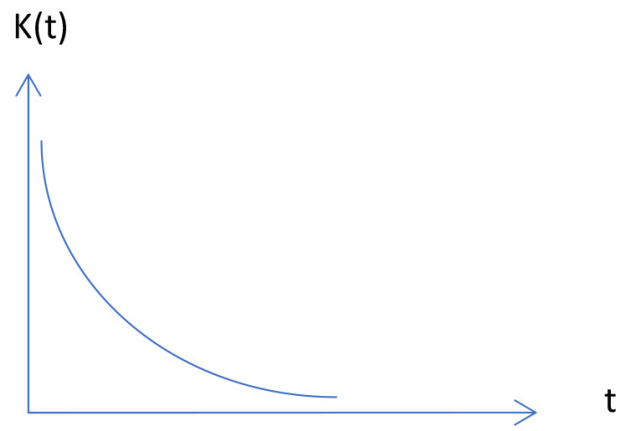

Figure 3. Income tax rate and the importance of the public good.

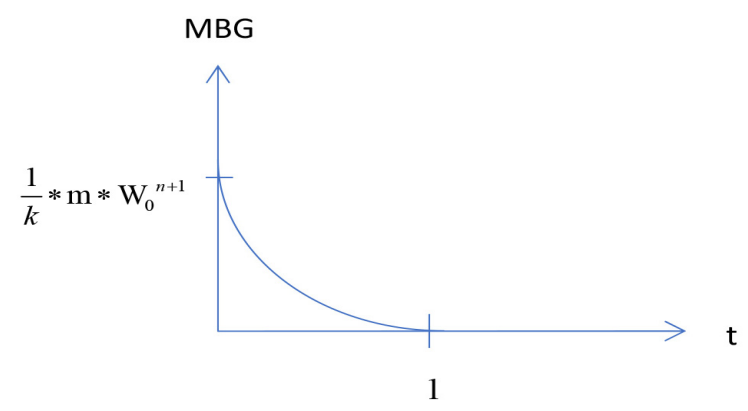

Figure 4. Income tax rate and the marginal benefit from public good.

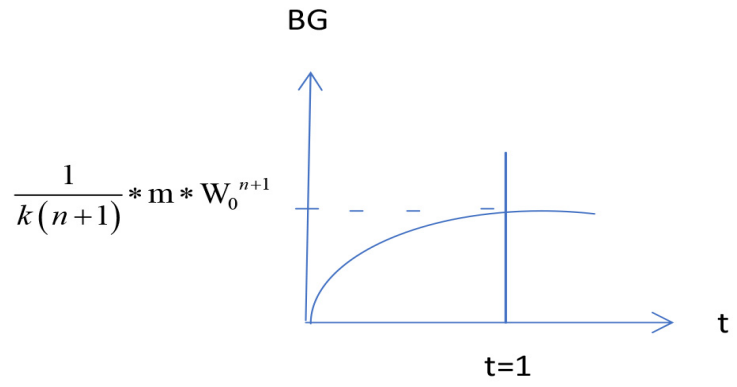

Figure 5. Income tax rate and the total benefit from the supply of public goods.

and he also benefits from the increase in government services (assuming that taxes finance government expenses). As we wrote before, given the agent's utility from leisure and consumption, the agent will choose an optimal number of leisure hours that fulfills condition (1).

Let us define $z(x)=\frac{m u(x)}{p}$, to get from Equation (1) that:

$$
m u(L)=z(x) W_{0}
$$

With the specification of utility function in (6), we can calculate $Z(x)$ by deriving $U(X, L)$ with respect to $X$ :

$$
Z(X)=M U(X)=\beta X^{\beta-1}=\beta\left[W_{0}(1-t)(24-L)\right]^{\beta-1}
$$


and

$$
\begin{aligned}
M B L & =M U(L)=W_{0} Z(X)=W_{0} \beta\left[W_{0}(1-t)(24-L)\right]^{\beta-1} \\
& =W_{0}^{\beta} \beta(1-t)^{\beta-1}(24-L)^{\beta-1}
\end{aligned}
$$

Integrating on $M B L$ and calculating the benefit from increasing leisure level from $L_{0}$ to $L_{1}$ following the increase in the tax rate from 0 to $t$, and given $W_{0}$ is the gross wage per hour, we get that $B L$ equals (see Appendix 1):

$$
B L(L)=\int_{L_{0}}^{L_{1}} M B L=W_{0}^{\beta(1+n)}(1-t)^{\beta-1} m^{\beta}\left[1-(1-t)^{n \beta}\right]
$$

\subsection{The Optimal Tax Rate}

As we mentioned before, the target function that should be maximized is the individual's tax benefit minus tax disadvantages:

$$
B G(t)-B G(0)+[B L-B X]
$$

Substituting (16), (20) and (24) into (5) we get:

$$
\begin{aligned}
& B G(t)-B G(0)+[B L-B X] \\
& =\frac{1}{k(n+1)} * m * W_{0}^{n+1} *\left(1-(1-t)^{n+1}\right) \\
& \quad+\left[W_{0}^{\beta(1+n)}(1-t)^{\beta-1} m^{\beta}\left[1-(1-t)^{n \beta}\right]-\left(h_{0} W_{0}\right)^{\beta}+\left(h_{0} W_{0}-h_{1} W_{0}(1-t)\right)^{\beta}\right]
\end{aligned}
$$

Simplifying the expression above (see Appendix 2), we get:

$$
\begin{aligned}
B G(t)-B G(0)+[B L-B X] \\
=\frac{1}{k(n+1)} * m * W_{0}^{n+1}-\frac{1}{k(n+1)} * m * W_{0}^{n+1} *(1-t)^{n+1} \\
\quad+W_{0}^{\beta(1+n)}(1-t)^{\beta-1} m^{\beta}-W_{0}^{\beta(1+n)}(1-t)^{\beta-1} m^{\beta}(1-t)^{n \beta} \\
\quad-\left(m * W W_{0}^{n+1}\right)^{\beta}+m^{\beta} W_{0}^{\beta(n+1)}\left(1-(1-t)^{n+1}\right)^{\beta}
\end{aligned}
$$

The government should maximize the Equation in (25') in order to find the optimal income tax rate that should be imposed.

Deriviating the target function with respect to the income tax rate $t$ and setting it equal to zero, we get:

$$
\begin{aligned}
& \frac{\mathrm{d}}{\mathrm{d} t}\left\{\frac{1}{k(n+1)} * m * W_{0}^{n+1}-\frac{1}{k(n+1)} * m * W_{0}^{n+1} *(1-t)^{n+1}\right. \\
& +W_{0} W^{\beta(1+n)}(1-t)^{\beta-1} m^{\beta}-W_{0}^{\beta(1+n)}(1-t)^{\beta-1} m^{\beta}(1-t)^{n \beta} \\
& \left.-\left(m * W W_{0}^{n+1}\right)^{\beta}+m^{\beta} W_{0}^{\beta(n+1)}\left(1-(1-t)^{n+1}\right)^{\beta}\right\}=0
\end{aligned}
$$

Avoiding all expressions that do not depend on $t$, we get:

$$
\begin{aligned}
& \frac{\mathrm{d}}{\mathrm{d} t}\left\{-\frac{1}{k(n+1)} * m * W_{0}^{n+1} *(1-t)^{n+1}+W_{0}^{\beta(1+n)}(1-t)^{\beta-1} m^{\beta}\right. \\
& \left.-W_{0}^{\beta(1+n)}(1-t)^{\beta-1} m^{\beta}(1-t)^{n \beta}+m^{\beta} W W_{0}^{\beta(n+1)}\left(1-(1-t)^{n+1}\right)^{\beta}\right\}
\end{aligned}
$$




$$
\begin{aligned}
= & \frac{1}{k} * m * W_{0}^{n+1} *(1-t)^{n}-W_{0} W^{\beta(1+n)}(1-t)^{\beta-2} m^{\beta}(\beta-1) \\
& +(\beta-1) W_{0}^{\beta(1+n)}(1-t)^{\beta-2} m^{\beta}(1-t)^{n \beta}+W_{0}^{\beta(1+n)}(1-t)^{\beta-1} m^{\beta} n \beta(1-t)^{n \beta-1}\left(26^{\prime}\right) \\
& +\beta m^{\beta} W W_{0}^{\beta(n+1)}\left(1-(1-t)^{n+1}\right)^{\beta-1}(n+1)(1-t)^{n}=0
\end{aligned}
$$

The optimal tax rate $t$ will make Equation (26') above equal to zero.

\section{Empirical Analysis}

Equation (26') determines the optimal tax rate given: $n, m, \beta, W_{0}$ and $k$.

In order to examine how changes in labor supply elasticity $(n)$, wage level $\left(W_{0}\right)$ and the public marginal benefit parameter $(K)$ affect the optimal tax rate, we first assumed a given level of these parameters and calculated the optimal income tax rate that equalizes Equation (26') to zero. Then, we gradually changed the level of the parameters and recalculated the new optimal income tax rate that Equalized (26') to zero.

\subsection{Elasticity of Labor Supply and Optimal Tax Rate}

As the base case example, we assumed that $W_{0}=1, K=10$, beta $=0.2$. We let $n$ be equal to $0.2,0.4,0.6,0.8,1$ and $m$ to be equal to $0.2,0.6,1,1.4$. For these numbers, the optimal tax rates are:

\begin{tabular}{ccccc}
\hline \multicolumn{4}{c}{ Optimal tax rates } \\
\hline$n \backslash m$ & 0.2 & 0.6 & 1 & 1.4 \\
\hline 0.2 & $46.24 \%$ & $45.79 \%$ & $46.51 \%$ & $47.50 \%$ \\
0.4 & $45.60 \%$ & $46.74 \%$ & $47.74 \%$ & $48.66 \%$ \\
0.6 & $46.87 \%$ & $36.40 \%$ & $37.06 \%$ & $37.67 \%$ \\
0.8 & $36.48 \%$ & $37.20 \%$ & $37.82 \%$ & $38.39 \%$ \\
1 & $37.29 \%$ & $37.96 \%$ & $38.45 \%$ & $38.85 \%$ \\
\hline
\end{tabular}

Conclusions: 1) as $n$ labor supply elasticity increases, the optimal tax rate decreases, and 2) as $m$ increases, the optimal tax rate increases.

\subsection{Utility from Public Good to the Public and Optimal Tax Rate}

Notice that as $K$ is larger the importance of the public good for individuals is lower. We now examine how the optimal tax rate changes as $K$ changes. We let $K$ vary and be equal to $10,50,100,200$. The optimal tax rates for the different $K$-s are:

$K=10$ (the base-case example):

\begin{tabular}{ccccc}
\hline \multicolumn{5}{c}{ Optimal tax rates } \\
\hline$n \backslash m$ & 0.2 & 0.6 & 1 & 1.4 \\
\hline 0.2 & $46.24 \%$ & $45.79 \%$ & $46.51 \%$ & $47.50 \%$ \\
0.4 & $45.60 \%$ & $46.74 \%$ & $47.74 \%$ & $48.66 \%$ \\
0.6 & $46.87 \%$ & $36.40 \%$ & $37.06 \%$ & $37.67 \%$ \\
0.8 & $36.48 \%$ & $37.20 \%$ & $37.82 \%$ & $38.39 \%$ \\
1 & $37.29 \%$ & $37.96 \%$ & $38.45 \%$ & $38.85 \%$ \\
\hline
\end{tabular}


$K=50$ :

\begin{tabular}{ccccc}
\hline \multicolumn{5}{c}{ Optimal tax rates } \\
\hline$n \backslash m$ & 0.2 & 0.6 & 1 & 1.4 \\
\hline 0.2 & No solution & $45.54 \%$ & $45.87 \%$ & $46.17 \%$ \\
0.4 & $44.95 \%$ & $45.18 \%$ & $45.37 \%$ & $45.55 \%$ \\
0.6 & $46.26 \%$ & $46.48 \%$ & $46.66 \%$ & $46.83 \%$ \\
0.8 & $36.08 \%$ & $36.22 \%$ & $36.34 \%$ & $36.46 \%$ \\
1 & $36.90 \%$ & $37.04 \%$ & $37.15 \%$ & $37.26 \%$ \\
\hline
\end{tabular}

$K=100$ :

\begin{tabular}{ccccc}
\hline \multicolumn{5}{c}{ Optimal tax rates } \\
\hline$n \backslash m$ & 0.2 & 0.6 & 1 & 1.4 \\
\hline 0.2 & No solution & No solution & $45.38 \%$ & $45.53 \%$ \\
0.4 & $44.87 \%$ & $44.98 \%$ & $45.08 \%$ & $45.17 \%$ \\
0.6 & $46.19 \%$ & $46.29 \%$ & $46.39 \%$ & $46.47 \%$ \\
0.8 & $36.03 \%$ & $36.10 \%$ & $36.16 \%$ & $36.22 \%$ \\
1 & $36.86 \%$ & $36.92 \%$ & $36.98 \%$ & $37.03 \%$ \\
\hline
\end{tabular}

$K=200$ :

\begin{tabular}{ccccc}
\hline \multicolumn{4}{c}{ Optimal tax rates } \\
\hline$n \backslash m$ & 0.2 & 0.6 & 1 & 1.4 \\
\hline 0.2 & No solution & No solution & No solution & No solution \\
0.4 & $44.83 \%$ & $44.89 \%$ & $44.94 \%$ & $44.98 \%$ \\
0.6 & $46.15 \%$ & $46.20 \%$ & $46.25 \%$ & $46.29 \%$ \\
0.8 & $36.00 \%$ & $36.04 \%$ & $36.07 \%$ & $36.10 \%$ \\
1 & $36.83 \%$ & $36.86 \%$ & $36.89 \%$ & $36.92 \%$ \\
\hline
\end{tabular}

Conclusion: 3) As $K$ increases, the optimal tax rate decreases.

\subsection{Wage Level and Optimal Tax Rate}

Next, we examine how the optimal tax rate changes as $W_{0}$ changes. We let $W_{0}$ vary and be equal to $1,1.5,2$. The optimal tax rates for the different $W_{0}$ 's are:

$W_{0}=1$ (base-case example):

\begin{tabular}{ccccc}
\hline \multicolumn{5}{c}{ Optimal tax rates } \\
\hline$n \backslash m$ & 0.2 & 0.6 & 1 & 1.4 \\
\hline 0.2 & $46.24 \%$ & $45.79 \%$ & $46.51 \%$ & $47.50 \%$ \\
0.4 & $45.60 \%$ & $46.74 \%$ & $47.74 \%$ & $48.66 \%$ \\
0.6 & $46.87 \%$ & $36.40 \%$ & $37.06 \%$ & $37.67 \%$ \\
0.8 & $36.48 \%$ & $37.20 \%$ & $37.82 \%$ & $38.39 \%$ \\
1 & $37.29 \%$ & $37.96 \%$ & $38.45 \%$ & $38.85 \%$ \\
\hline
\end{tabular}


$W_{0}=1.5:$

\begin{tabular}{ccccc}
\hline \multicolumn{5}{c}{ Optimal tax rates } \\
\hline$n \backslash m$ & 0.2 & 0.6 & 1 & 1.4 \\
\hline 0.2 & No solution & $46.45 \%$ & $48.03 \%$ & $49.51 \%$ \\
0.4 & $46.06 \%$ & $47.88 \%$ & $49.46 \%$ & $50.95 \%$ \\
0.6 & $36.01 \%$ & $37.29 \%$ & $38.40 \%$ & $39.31 \%$ \\
0.8 & $36.88 \%$ & $38.17 \%$ & $39.15 \%$ & $39.31 \%$ \\
1 & $37.72 \%$ & $38.80 \%$ & $39.31 \%$ & $39.31 \%$ \\
\hline
\end{tabular}

$W_{0}=2:$

\begin{tabular}{ccccc}
\hline \multicolumn{5}{c}{ Optimal tax rates } \\
\hline$n \backslash m$ & 0.2 & 0.6 & 1 & 1.4 \\
\hline 0.2 & No solution & $47.45 \%$ & $49.55 \%$ & $51.53 \%$ \\
0.4 & $46.55 \%$ & $49.07 \%$ & $51.29 \%$ & $52.11 \%$ \\
0.6 & $36.41 \%$ & $38.27 \%$ & $39.31 \%$ & $39.31 \%$ \\
0.8 & $37.35 \%$ & $39.17 \%$ & $39.31 \%$ & $39.31 \%$ \\
1 & $38.25 \%$ & $39.31 \%$ & $39.31 \%$ & $39.31 \%$ \\
\hline
\end{tabular}

Conclusion: 4) there is a $\mathrm{U}$ shape, at first as $W_{0}$ increases, the optimal tax rate decreases, but when $W_{0}$ keep growing the tax rate increases.

\section{Summary}

In this paper, we suggested a model that enables us to calculate the optimal income tax rate, taking into consideration that the imposition of income tax will reduce working hours, increase leisure, and increase the supply of public goods. Other researchers such as [2] and [3] optimized the income tax over the population by selecting the tax rate that maximizes the social utility objective function. Instead of looking at the problem from a central planner's point of view, we suggest that the optimal tax rate should be defined according to each private agent's point of view.

We take into consideration a given labor supply function derived from a given utility function from consumption and leisure, as well as a given utility function from public goods. When the government imposes an income tax, utility from consumption would reduce while utility from leisure and from consumption of public goods would increase. When taking into consideration all factors that affect utility, we maximized the utility subject to the income tax rate and found the optimal tax rate for various levels of labor supply elasticity, various levels of wage per hour, and various levels of marginal utility from the public good.

According to our finding, as the elasticity of labor supply increases, tax rate should be deceased. Such a result is not surprising since imposition of tax under such conditions would cause a large decrease in the supply of labor, a large de- 
crease in private consumption and in an individual's utility. The negative effect of income tax on labor supply is a well-known fact that was supported by many researchers. For example, [11] [12] [13] attributed high labor income taxes in Europe as one of the important determinant of declining labor supply in Europe. Other studies by [14] [15] [16] and [17], among others, have uncovered that high labor income taxes in Europe are an important determinant of declining labor supply in Europe. There has long existed a broad consensus among researchers that the female labor supply is more elastic than male labor supply (see, for example, [18]). Our results unsurprisingly suggest that in order to avoid a large decrease in employment of sectors with high labor supply elasticity (such as females) and a large reduction in utility, we should be cautious when considering increasing income tax rate.

We also find that there is a U-shape relation between gross wage and optimal income tax. At low gross wage per hour, taxes should be reduced while when wage per hour in high, the optimal tax rate should increase. [3] got the same result, although he used a different utility function and a different method while the work of [19] and [2] support the idea that optimal tax rate should decline with income.

Finally, we were not surprised to find that as utility from public goods decrease, the optimal tax rate decreases.

\section{Conflicts of Interest}

The authors declare no conflicts of interest regarding the publication of this paper.

\section{References}

[1] Katz, M.L. and Rosen, H. (1991) Microeconomics. Irwin, Boston, MA.

[2] Mirrlees, J.A. (1971) An Exploration in the Theory of Optimum Income Taxation. The Review of Economic Studies, 38, 175-208. https://doi.org/10.2307/2296779

[3] Diamond, P.A. (1998) Optimal Income Taxation: An Example with a U-Shaped Pattern of Optimal Marginal Tax Rates. American Economic Review, 88, 83-95.

[4] Diamond, P.A. (1980) Income Taxation with Fixed Hours of Work. Journal of Public Economics, 13, 101-110. https://doi.org/10.1016/0047-2727(80)90024-9

[5] Laroque, G. (2005) Income Maintenance and Labor Supply Force Participation, Econometrica, 73, 341-376. https://doi.org/10.1111/j.1468-0262.2005.00582.x

[6] Hokayem, C. and Ziliak, J.P. (2014) Health, Human Capital, and Life Cycle Labor Supply. The American Economic Review, 104, 127-131.

https://doi.org/10.1257/aer.104.5.127

[7] Averett, S.L. and Hotchkiss, J.L. (1997) Female Labor Supply with a Discontinuous, Nonconvex Budget Constraint: Incorporation of a Part-Time/Full-Time Wage Differential. The Review of Economics and Statistics, 79, 461-470. https://doi.org/10.1162/003465300556878

[8] Hansson, I. and Stuart, C. (1985) Tax Revenue and the Marginal Cost of Public Funds in Sweden. Journal of Public Economics, 27, 331-353.

https://doi.org/10.1016/0047-2727(85)90055-6 
[9] Gautam, A.B., Strand, I. and Kirkley, J. (1996) Leisure/Labor Tradeoffs: The Backward-Bending Labor Supply in Fisheries. Journal of Environmental Economics and Management, 31, 352-367. https://doi.org/10.1006/jeem.1996.0049

[10] Heckman, J., Killingsworth, M.R. and MaCurdy, T. (1981) Empirical Evidence on Static Labor Supply Models: A Survey of Recent Developments. In: Hornstein, Z., Grice, J. and Webb, A., Eds., The Economics of the Labor Market, HMSO, London.

[11] Prescott, E.C. (2002) Prosperity and Depression. The American Economic Review, 92, 1-15. https://doi.org/10.1257/000282802320188916

[12] Prescott, E.C. (2004) Why Do Americans Work So Much More than Europeans? National Bureau of Economic Research. https://doi.org/10.3386/w10316

[13] Prescott, E.C. (2006) Nobel Lecture: The Transformation of Macroeconomic Policy and Research. Journal of Political Economy, 114, 203-235. https://doi.org/10.1086/503205

[14] Ohanian, L., Raffo, A. and Rogerson, R. (2008) Long-Term Changes in Labor Supply and Taxes: Evidence from OECD Countries, 1956-2004. Journal of Monetary Economics, 55, 1353-1362. https://doi.org/10.1016/j.jmoneco.2008.09.012

[15] Rogerson, R. (2008) Structural Transformation and the Deterioration of European Labor Market Outcomes. Journal of Political Economy, 116, 235-259. https://doi.org/10.1086/588029

[16] Rogerson, R. and Wallenius, J. (2009) Micro and Macro Elasticities in a Life Cycle Model with Taxes. Journal of Economic Theory, 144, 2277-2292.

https://doi.org/10.1016/j.jet.2008.05.011

[17] Krusell, P., Mukoyama, T., Rogerson, R. and Şahin, A. (2010) Aggregate Labor Market Outcomes: The Roles of Choice and Chance. Quantitative Economics, 1, 97-127. https://doi.org/10.3982/QE7

[18] Heim, B.T. (2007) The Incredible Shrinking Elasticities Married Female Labor Supply, 1978-2002. Journal of Human Resources, 42, 881-918. https://doi.org/10.3368/jhr.XLII.4.881

[19] Slemrod, J., Yitzhaki, S., Mayshar, J. and Lundholm, M. (1994) The Optimal TwoBracket Linear Income Tax. Journal of Public Economics, 53, 269-290. https://doi.org/10.1016/0047-2727(94)90024-8

[20] Gios, G. and Notaro, S. (2001) La valutazione economica dei beni ambientali: Introduzione al metodo della valutazione contingente. Cedam.

[21] Hausman, J.A. (1993) Contingent Valuation: A Critical Assessment. Emerald Group Publishing Limited, Bingley, West Yorkshire. https://doi.org/10.1108/S0573-8555(1993)220

[22] Knetsch, J.L. (2000) Environmental Valuations and Standard Theory: Behavioural Findings, Context Dependence and Implications. In: Tietenberg, T. and Folmer, H., Eds., The International Yearbook of Environmental and Resource Economics 2000/2001, Springer, New York, 267-299.

[23] Mitchell, R.C. and Carson, R.T. (1989) Using Surveys to Value Public Goods: The Contingent Valuation Method. Resources for the Future.

[24] Samuelson, P.A. (1954) The Pure Theory of Public Expenditure. The Review of Economics and Statistics, 36, 387-389. https://doi.org/10.2307/1925895

[25] Kaplow, L. (2008) The Theory of Taxation and Public Economics. Princeton University Press, Princeton, NJ. https://doi.org/10.2139/ssrn.1155194 


\section{Appendix 1}

$$
\begin{aligned}
B L(L) & =\int_{L_{0}}^{L_{1}} M B L=\int_{L_{0}}^{L_{1}} W_{0}^{\beta} \beta(1-t)^{\beta-1}(24-L)^{\beta-1} \mathrm{~d} L \\
& =W_{0} \beta(1-t)^{\beta-1} \int_{L_{0}}^{L_{1}}(24-L)^{\beta-1} \mathrm{~d} L \\
& =W_{0}^{\beta} \beta(1-t)^{\beta-1} \int_{L_{0}}^{L_{1}}(24-L)^{\beta-1} \mathrm{~d} L \\
& =\left[W_{0}^{\beta} \beta(1-t)^{\beta-1} \frac{-(24-L)^{\beta}}{\beta}\right]_{L_{0}}^{L_{1}} \\
& =\left[-W_{0}^{\beta}(1-t)^{\beta-1}(24-L)^{\beta}\right]_{L_{0}}^{L_{1}} \\
& =-W_{0}^{\beta}(1-t)^{\beta-1}\left(24-L_{1}\right)^{\beta}-\left[-W_{0}^{\beta}(1-t)^{\beta-1}\left(24-L_{0}\right)^{\beta}\right] \\
& =-W_{0}^{\beta}(1-t)^{\beta-1}\left(24-L_{1}\right)^{\beta}+W_{0}^{\beta}(1-t)^{\beta-1}\left(24-L_{0}\right)^{\beta} \\
& =W_{0}^{\beta}(1-t)^{\beta-1}\left[\left(24-L_{0}\right)^{\beta}-\left(24-L_{1}\right)^{\beta}\right]
\end{aligned}
$$

Recall that: $L_{0}=24-m * W_{0}^{n}$ and $L_{1}=24-m * W_{0}^{n} *(1-t)^{n}$.

Incorporating $L_{0}, L_{1}$ into $B L(L)$ :

$$
\begin{aligned}
& W_{0}^{\beta}(1-t)^{\beta-1}\left[\left(24-\left(24-m * W_{0}^{n}\right)\right)^{\beta}-\left(24-\left(24-m * W_{0}^{n} *(1-t)^{n}\right)\right)^{\beta}\right] \\
& =W_{0}^{\beta}(1-t)^{\beta-1}\left[\left(m * W_{0}^{n}\right)^{\beta}-\left(m * W_{0}^{n} *(1-t)^{n}\right)^{\beta}\right] \\
& =W_{0}^{\beta}(1-t)^{\beta-1}\left(m * W_{0}^{n}\right)^{\beta}\left[1-(1-t)^{n \beta}\right] \\
& =W_{0} W^{\beta(1+n)}(1-t)^{\beta-1} m^{\beta}\left[1-(1-t)^{n \beta}\right]
\end{aligned}
$$

\section{Appendix 2}

$$
\begin{aligned}
& B G(t)-B G(0)+[B L-B X] \\
= & \frac{1}{k(n+1)} * m * W_{0}^{n+1} *\left(1-(1-t)^{n+1}\right)+W_{0}^{\beta(1+n)}(1-t)^{\beta-1} m^{\beta}\left[1-(1-t)^{n \beta}\right] \\
& -\left(h_{0} W_{0}\right)^{\beta}+\left(h_{0} W_{0}-h_{1} W_{0}(1-t)\right)^{\beta} \\
= & \frac{1}{k(n+1)} * m * W_{0}^{n+1}-\frac{1}{k(n+1)} * m * W_{0}^{n+1} *(1-t)^{n+1}+W_{0}^{\beta(1+n)}(1-t)^{\beta-1} m^{\beta} \\
& -W_{0}^{\beta(1+n)}(1-t)^{\beta-1} m^{\beta}(1-t)^{n \beta}-\left(h_{0} W_{0}\right)^{\beta}+\left(h_{0} W_{0}-h_{1} W_{0}(1-t)\right)^{\beta}
\end{aligned}
$$

Substituting $h_{0}=m * W_{0}^{n}$ and $h_{1}=m * W_{0}^{n} *(1-t)^{n}$ we get:

$$
\begin{aligned}
& \frac{1}{k(n+1)} * m * W_{0}^{n+1}-\frac{1}{k(n+1)} * m * W_{0}^{n+1} *(1-t)^{n+1} \\
& +W_{0}^{\beta(1+n)}(1-t)^{\beta-1} m^{\beta}-W_{0}^{\beta(1+n)}(1-t)^{\beta-1} m^{\beta}(1-t)^{n \beta} \\
& -\left(m * W_{0}^{n} W_{0}\right)^{\beta}+\left(m * W_{0}^{n} W_{0}-m * W_{0}^{n} *(1-t)^{n} W_{0}(1-t)\right)^{\beta} \\
& =\frac{1}{k(n+1)} * m * W_{0}^{n+1}-\frac{1}{k(n+1)} * m * W_{0}^{n+1} *(1-t)^{n+1} \\
& +W_{0}^{\beta(1+n)}(1-t)^{\beta-1} m^{\beta}-W_{0}^{\beta(1+n)}(1-t)^{\beta-1} m^{\beta}(1-t)^{n \beta}
\end{aligned}
$$




$$
\begin{aligned}
& -\left(m * W_{0}^{n+1}\right)^{\beta}+\left(m * W_{0}^{n+1}-m * W_{0}^{n+1} *(1-t)^{n+1}\right)^{\beta} \\
= & \frac{1}{k(n+1)} * m * W_{0}^{n+1}-\frac{1}{k(n+1)} * m * W_{0}^{n+1} *(1-t)^{n+1} \\
& +W_{0}^{\beta(1+n)}(1-t)^{\beta-1} m^{\beta}-W_{0}^{\beta(1+n)}(1-t)^{\beta-1} m^{\beta}(1-t)^{n \beta} \\
& -\left(m * W_{0}^{n+1}\right)^{\beta}+\left(m * W_{0}^{n+1}\left(1-(1-t)^{n+1}\right)\right)^{\beta} \\
= & \frac{1}{k(n+1)} * m * W_{0}^{n+1}-\frac{1}{k(n+1)} * m * W_{0}^{n+1} *(1-t)^{n+1} \\
& +W_{0}^{\beta(1+n)}(1-t)^{\beta-1} m^{\beta}-W_{0}^{\beta(1+n)}(1-t)^{\beta-1} m^{\beta}(1-t)^{n \beta} \\
& -\left(m * W_{0}^{n+1}\right)^{\beta}+m^{\beta} W_{0}^{\beta(n+1)}\left(1-(1-t)^{n+1}\right)^{\beta}
\end{aligned}
$$

